\title{
A NOVEL REVERSE-PHASE HIGH-PERFORMANCE LIQUID CHROMATOGRAPHIC METHOD FOR SIMULTANEOUS ESTIMATION OF ELLAGIC ACID, QUERCETIN, AND PIPERINE IN AYURVEDIC FORMULATIONS
}

\author{
SULTANA SHAIKH, VANDANA JAIN* \\ Department of Quality Assurance, Oriental College of Pharmacy, Mumbai, Maharashtra, India. Email: vandana.jain@ocp.edu.in
} Received: 05 February 2018, Revised and Accepted: 15 March 2018

\section{ABSTRACT}

Objective: The objective of the study was to develop a novel, accurate, precise, and linear reverse-phase high-performance liquid chromatographic (RP-HPLC) method for simultaneous qualitative and quantitative estimation of ellagic acid, quercetin, and piperine in different Ayurvedic formulations and validate as per the International Conference on Harmonization guidelines.

Methods: In the present work, a good chromatographic separation was achieved isocratically using a shim-pack HPLC C18 column $(4.6 \times 250 \mathrm{~mm}$, $5 \mu \mathrm{m}$ ) and a mobile phase consisting of $0.02 \mathrm{M}$ potassium dihydrogen orthophosphate buffer (pH adjusted to 3.5 with orthophosphoric acid) and acetonitrile in the ratio $60: 40$, a flow rate of $1.2 \mathrm{ml} / \mathrm{min}$ and column temperature maintained at $35^{\circ} \mathrm{C}$. The effluents obtained were monitored at $255 \mathrm{~nm}$ with ultraviolet-visible detector.

Results: The retention time of ellagic acid, quercetin, and piperine was found to be $1.65 \mathrm{~min}, 2.94 \mathrm{~min}$, and 14.57 min, respectively. The linearity of ellagic acid, quercetin, and piperine was tested in the range of 6-14 ppm, 3-11 ppm, and 3-13 ppm, respectively. The correlation coefficient for ellagic acid, quercetin, and piperine was found to be $0.997,0.993$, and 0.99 , respectively. The high recovery values (98-102\%) indicate a satisfactory accuracy. The low percent relative standard deviation values in the precision study reveal that the method is precise.

Conclusion: The developed method is novel, simple, precise, rapid, accurate, and reproducible for simultaneous quantitative estimation of ellagic acid, quercetin, and piperine in Ayurvedic formulations. Hence, the developed method can be used for quantitative analysis and quality control of extracts and commercial samples of other plant species and formulations containing these three markers.

Keywords: Ellagic acid, Quercetin, Piperine, Ayurvedic formulation, Reverse-phase high-performance liquid chromatographic, Validation, International Conference on Harmonization.

(c) 2018 The Authors. Published by Innovare Academic Sciences Pvt Ltd. This is an open access article under the CC BY license (http://creativecommons. org/licenses/by/4. 0/) DOI: http://dx.doi.org/10.22159/ajpcr.2018.v11i6.25627

\section{INTRODUCTION}

Standardization and analysis of chemical markers in ayurvedic or complex polyherbal formulations are always a challenging task. Quantitative determination of chemical markers of each crude drug in any polyherbal preparation required optimal separation techniques by which these markers are separated with the highest resolution and least interference from each other [1]. Herbal medicine has been enjoying revitalization among the customers throughout the world. However, one of the impediments in the acceptance of the ayurvedic medicines is the lack of standard quality control profiles. The quality of herbal medicine, i.e., the profile of the constituents in the final product, has implication in efficacy and safety. Due to the complex nature and inherent variability of the chemical constituent of plant-based drugs, it is difficult to establish quality control parameters. Modern analytical techniques are increasing to overcome these complications [2]. Separation, identification, and determination of chemical components are very problematic for such complex polyherbal formulations. The advances in chromatographic separation techniques made it possible to quantify the chemical constituents in a mixture with comparatively little clean-up [3]. Particularly, methods using high-performance liquid chromatographic (HPLC) with reversed phase columns are most commonly applied for the analysis of multiple constituents present in medicinal plants and herbal preparations. Hence, herbal drugs or pure active compound needs analytical techniques such as HPLC and highperformance thin layer chromatography to confirm its identity, quality, purity, potency, safety, and efficacy of the plant.
In the present study, we have selected two marketed ayurvedic dental powders, which are used to maintain oral hygiene. It is indicated for various dental problems and makes teeth and gums stronger. The selected ayurvedic formulations contain Terminalia bellirica (Combretaceae), Piper nigrum (Piperaceae), Terminalia chebula (Combretaceae), and other crude drugs. Three chemical markers were selected for quantification, namely, ellagic acid, quercetin, and piperine.

The literature survey reveals that various analytical methods for estimation of ellagic acid, quercetin, and piperine were reported alone and in combination with other drugs [4-10], but to the best of our knowledge, there is no such reported HPLC analysis method for simultaneous estimation of ellagic acid, quercetin, and piperine.

In the present investigation, we have developed a simple, optimized, and validated HPLC method for the standardization of ayurvedic formulations using three chemical markers, namely, ellagic acid, quercetin, and piperine. The method was validated as per the International Conference on Harmonization (ICH) guidelines. This novel validated method has wide applicability in industry as well as in academia.

\section{MATERIALS AND METHODS}

HPLC grade ellagic acid, quercetin, and piperine (purity 99\%) were procured as gift sample from Yucca Enterprises, Mumbai, India. An Ayurvedic preparation Vithoba dental powder (Vithoba Industries Pvt. Ltd.) and Dabur dental powder (Dabur India Ltd) used for analysis were 
purchased from local market. HPLC grade solvents were purchased from Thomas Baker. Reverse phase (RP)-HPLC Shimadzu (LC 2030) model with "Lab Solution" software was employed in this method. Analytical column used for the separation of analytes was shim-pack HPLC C18 $(250 \times 4.6 \mathrm{~mm}, 5 \mu \mathrm{m})$.

\section{Methods}

\section{Selection of wavelength}

The suitable wavelength for the HPLC analysis was determined by recording ultraviolet (UV) spectrums in the range of $200-400 \mathrm{~nm}$ for individual drug solutions of ellagic acid, quercetin, and piperine then overlapped. UV overlain spectra of these three markers showed that the drugs absorb appreciably at $255 \mathrm{~nm}$, and hence, $255 \mathrm{~nm}$ was taken as a detection wavelength for HPLC analysis (Fig. 1).

\section{Chromatographic conditions}

The method was developed using RP, shim-pack HPLC C18 column $(250 \times 4.6 \mathrm{~mm}, 5 \mu \mathrm{m})$. The runtime was of $16 \mathrm{~min}$. The mobile phase used was $0.02 \mathrm{M}$ potassium dihydrogen orthophosphate buffer ( $\mathrm{pH}$ adjusted to 3.5 with orthophosphoric acid) and acetonitrile in the ratio $60: 40$ at a flow rate of $1.2 \mathrm{ml} / \mathrm{min}$, column temperature maintained at $35^{\circ} \mathrm{C}$ and a detection wavelength of $255 \mathrm{~nm}$ using a UVvisible detector.

\section{Preparation of $0.02 \mathrm{M}$ phosphate buffer ( $\mathrm{pH}$ 3.5)}

About $3.48 \mathrm{~g}$ of potassium dihydrogen orthophosphate was accurately weighed and dissolved in $950 \mathrm{ml}$ of water. The $\mathrm{pH}$ was adjusted to 3.5 with orthophosphoric acid, and the volume was made up to $1000 \mathrm{ml}$ in a volumetric flask. The solution was then filtered using $0.45 \mu$ membrane filter.

\section{Preparation of standard solution}

About $100 \mathrm{mg}$ of ellagic acid, quercetin, and piperine standard were accurately weighed and transferred into $100 \mathrm{ml}$ volumetric flask, respectively. About $70 \mathrm{ml}$ solvent was added, sonicated to dissolve and diluted up to the mark using a solvent (1000 ppm). The final concentration of ellagic acid, quercetin, and piperine was made to $10 \mathrm{ppm}, 7 \mathrm{ppm}$, and $8 \mathrm{ppm}$, respectively, by suitable dilutions.

\section{Sample preparation}

Accurately, about $500 \mathrm{mg}$ of each dental powder was extracted separately with $100 \mathrm{ml}$ methanol in aliquots. The sample solution was filtered to obtain a clear solution. The stock solution of each formulation after suitable dilutions was used for further analysis.

\section{RESULTS AND DISCUSSION}

\section{Method development}

A novel RP-HPLC method was developed keeping in mind the system suitability parameters, i.e., resolution factor (R), tailing factor (T), number of theoretical plates $(\mathrm{N})$, runtime, and the cost-effectiveness. The developed optimized method resulted in the elution of ellagic acid at $1.65 \mathrm{~min}$, quercetin at $2.94 \mathrm{~min}$, and piperine at $14.57 \mathrm{~min}$. Figs. 2-4 represent chromatograms of ellagic acid, quercetin, and piperine standard solution, respectively. The total runtime was $16 \mathrm{~min}$. System suitability tests are an essential part of method development and are used to ensure satisfactory performance of the chromatographic system.

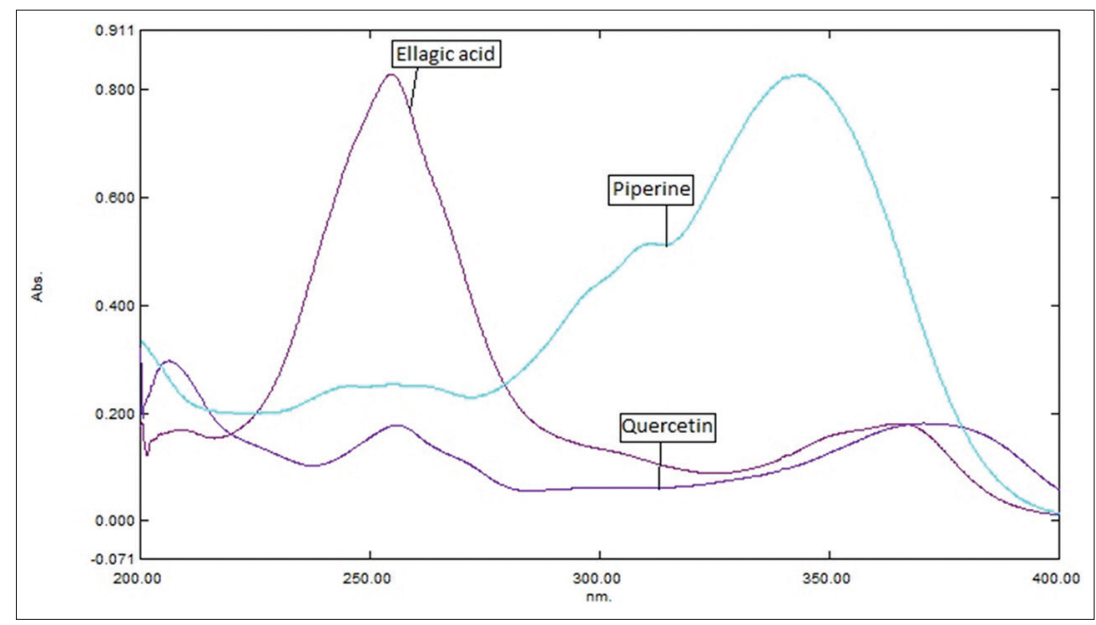

Fig. 1: Ultraviolet overlap spectrum of ellagic acid, quercetin and piperine

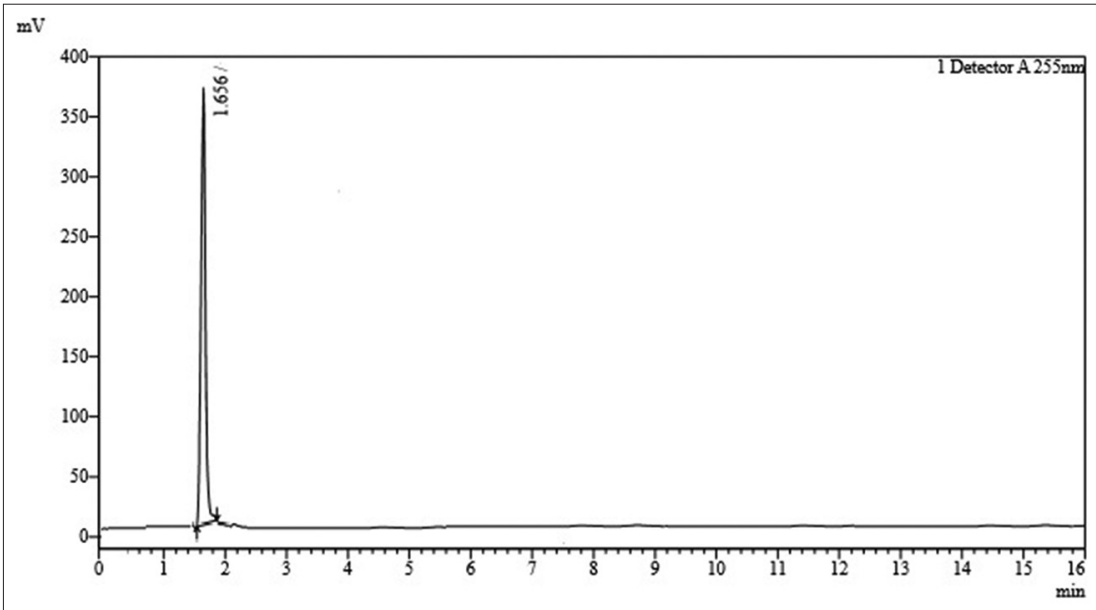

Fig. 2: Typical chromatogram of ellagic acid standard solution 
System suitability parameters, i.e., retention time (tR), the number of theoretical plates, and resolution and tailing factor were evaluated for six replicate injections of the standard working concentration. The results given in Table 1 were within the acceptable limits $[11,12]$.

To test the applicability of the developed method to ayurvedic formulations, dental powder extracts were chromatographed, and it is shown in Figs. 5 and 6. The sample peaks were identified by comparing the relative retention times with standard markers (Figs. 2-4). System suitability parameters were within the acceptable limits, ideal for the chromatographed sample. Integration of the separated peak area was done, and each marker concentration was determined using a linear regression equation. For the analysis of a sample, extract of $500 \mathrm{ppm}$ of dental powder was injected in triplicate and quantified for three active markers using a linear regression equation. The results of dental powder extract analysis are reported in Table 2.

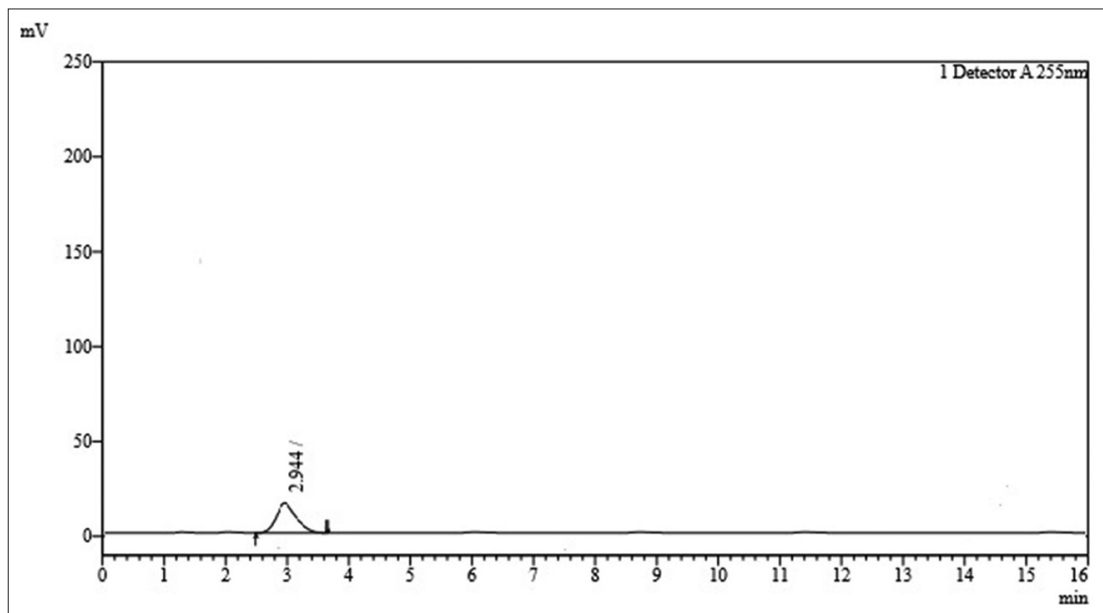

Fig. 3: Typical chromatogram of quercetin standard solution

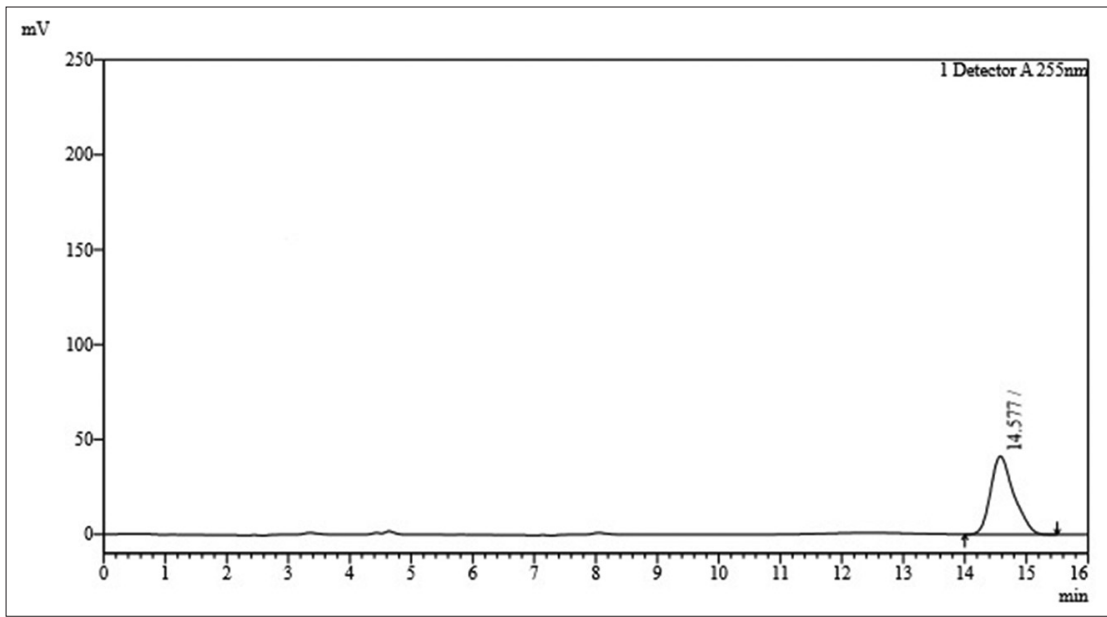

Fig. 4: Typical chromatogram of piperine standard solution

Table 1: Results of system suitability studies

\begin{tabular}{lllll}
\hline Parameters & Acceptance limits & Ellagic acid & Quercetin & Piperine \\
\hline Retention time (min) & - & 1.65 & 2.94 & 14.57 \\
Resolution factor & Not<2 & - & 8.04 & 13.00 \\
Number of theoretical plates & Not<2000 & 3608 & 3786 & 7343 \\
Tailing factor & Not more than 2 & 1.02 & 1.21 & 1.26 \\
\hline
\end{tabular}

Table 2: Analysis of ayurvedic dental powder extracts

\begin{tabular}{llll}
\hline Formulation & Marker & Amount found (ppm) $\mathbf{n = 3}$ & Content (\%) \\
\hline Ayurvedic dental powder extract (500 ppm) Vithoba & Ellagic acid & 7.00 & 1.40 \\
& Quercetin & 3.28 & 0.65 \\
Ayurvedic dental powder extract (500 ppm) Dabur & Piperine & 4.46 & 0.89 \\
& Ellagic acid & 3.58 & 0.71 \\
& Quercetin & 2.65 & 0.53 \\
\hline
\end{tabular}

${ }^{\#} \mathrm{n}$ : Number of injections 


\section{Method validation}

Analytical method validation is the process to substantiate that the analytical procedure used for a specific examination is appropriate for its designated purpose. Food and Drug Administration regulations quality standards such as ISO17025 necessitate analytical methods to be validated before and during routine use. The developed HPLC method was validated according to the ICH guidelines [13] for validation of analytical procedures. The method was validated for the parameters such as linearity, accuracy, system precision, method precision, robustness, limit of detection (LOD), and limit of quantitation (LOQ).

\section{Specificity}

Figs. 2-6 for standard marker solutions and sample chromatograms reveals that the peaks obtained in the standard solutions and sample solution at working concentrations are just because of the drugs and blank has no peak at the tR of ellagic acid, quercetin, and piperine.
Accordingly, it can be concluded that the method developed is said to be specific $[14,15]$.

\section{Precision}

System precision

Six replicate injections of the standard marker solutions at working concentration presented percent relative standard deviation (SD) (\% RSD) $<2$ concerning the peak area for each marker, which indicates the satisfactory reproducibility and thereby the precision of the system $[16,17]$. System precision results are tabulated in Table 3.

\section{Method precision}

Method precision was determined by performing the analysis of the sample under the test of repeatability at working concentration. Three injections of the sample from the same homogeneous mixture

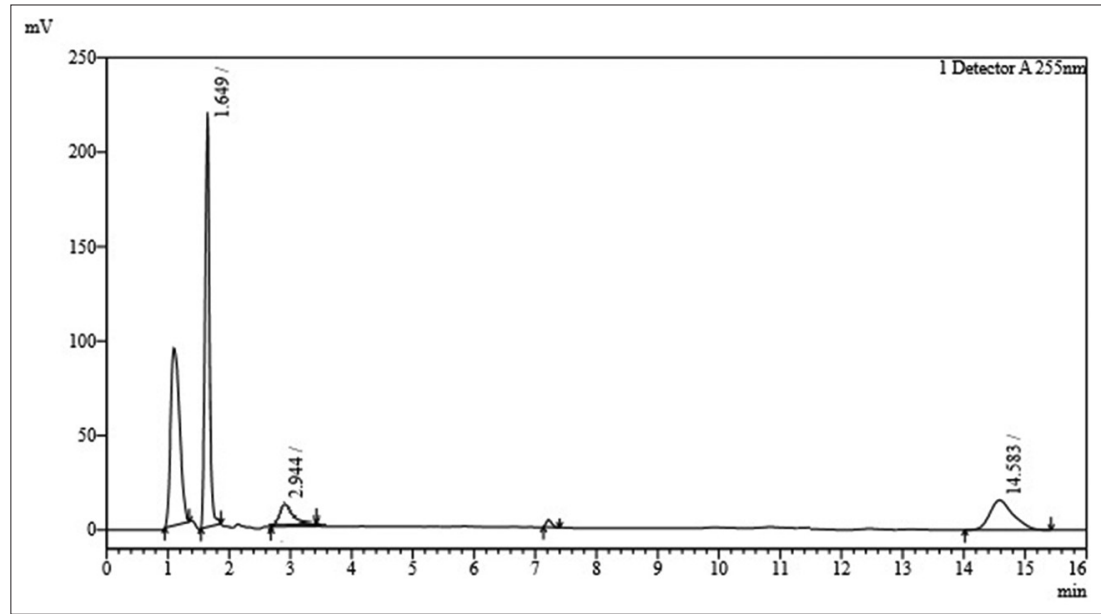

Fig. 5: Typical chromatogram of Vithoba ayurvedic formulation

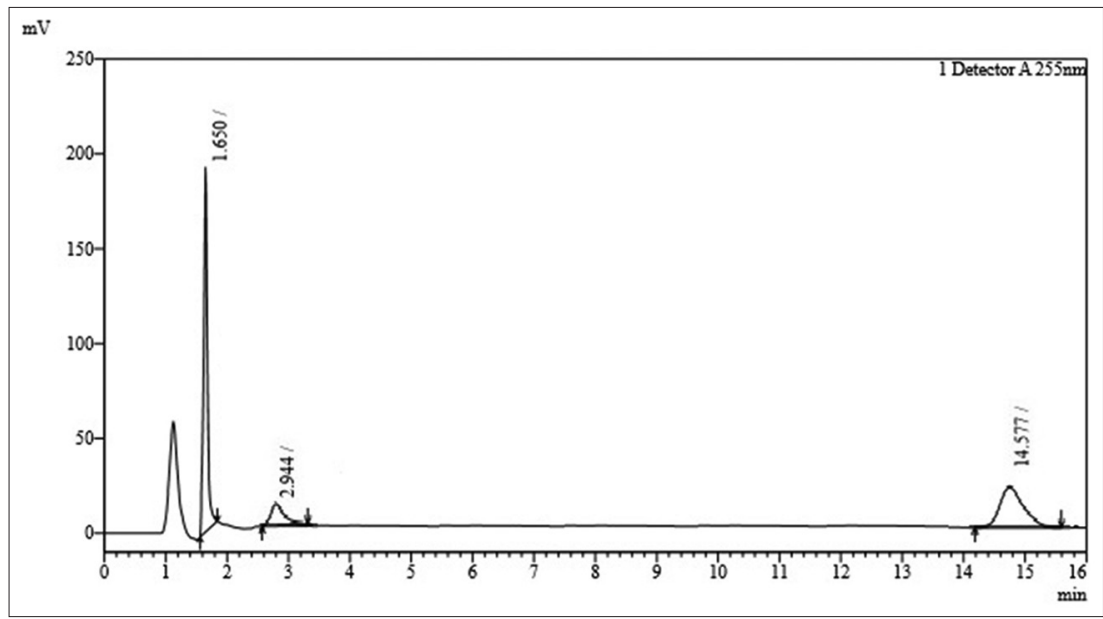

Fig. 6: Typical chromatogram of Dabur ayurvedic formulation

Table 3: System precision results

\begin{tabular}{llll}
\hline S. No & Peak area of ellagic acid $\mathbf{( 1 0} \mathbf{p p m})$ & Peak area of quercetin $\mathbf{( 7} \mathbf{p p m})$ & Peak area of piperine $\mathbf{( 8} \mathbf{~ p p m )}$ \\
\hline 1 & 1356692 & 405178 & 1085821 \\
2 & 1397586 & 409767 & 1087489 \\
3 & 1386532 & 402459 & 1097347 \\
4 & 1386582 & 409876 & 1076584 \\
5 & 1386239 & 403625 & 1097657 \\
6 & 1397528 & 402562 & 1086534 \\
Mean \pm SD & $1385193 \pm 14986$ & $405578 \pm 3430$ & $1088572 \pm 7952$ \\
$\%$ RSD & 1.08 & 0.85 & 0.73 \\
\hline
\end{tabular}

"SD: Standard deviation, ${ }^{\# \%}$ RSD: Percent relative standard deviation 
at working concentration showed $\% \mathrm{RSD}<2$ concerning the content of three markers indicate that the method developed is precise by the test of repeatability $[16,17]$, and hence can be understood that the method gives consistently reproducible results (Table 4 ).

\section{Linearity}

Standard solutions of ellagic acid, quercetin, and piperine at different concentration level were prepared in triplicates. Calibration curves were constructed by plotting the concentration level versus corresponding peak areas for each marker. The results show an excellent correlation between peak areas and concentrations level within the tested concentration range of 6-14 ppm for ellagic acid, 3-11 ppm for quercetin, and as that of 3-13 ppm for piperine. The correlation coefficients were $>0.99$ for each marker, which meets the method validation acceptance criteria [16,17]; hence, the method is said to be linear (Figs. 7-9).

\section{Accuracy}

Accuracy was determined by means of recovery experiments, by the determination of \% mean recovery of each compound in the formulation at three distinct levels $(80 \%, 100 \%$, and $120 \%)$. At each level, three determinations were performed. Percent mean recovery was calculated as shown in Table 5. The accepted limits of mean recovery are $98-102 \%$ and all observed data were within the range, which specifies good recovery values, supporting the accuracy of the method developed [16,17].

\section{Robustness}

To determine the robustness of the developed method, experimental conditions were purposely altered, and the system suitability parameter $\mathrm{T}$ and peak area were evaluated. The solution was prepared as per the test method described earlier and injected at different variable conditions such as column temperature $\left(33^{\circ} \mathrm{C}\right.$ and $\left.37^{\circ} \mathrm{C}\right)$, flow rate $(1.1 \mathrm{ml} / \mathrm{min}$ and $1.3 \mathrm{ml} / \mathrm{min}$ ), and detection wavelength (254 $\mathrm{nm}$ and $256 \mathrm{~nm}$ ). Robustness data clearly show that the proposed method is robust at small but deliberate change [16,17]. Robustness data are given in Table 6 .

\section{Sensitivity}

The sensitivity of measurement of ellagic acid, quercetin, and piperine by use of the proposed method was estimated in terms of the LOQ and LOD. LOQ and LOD were calculated using the equations $\mathrm{LOD}=3.3 \sigma / \mathrm{S}$ and $\mathrm{LOQ}=10 \sigma / \mathrm{S}$ where $\sigma$ is the SD of intercepts of calibration plots, and $\mathrm{S}$ is the average of the slopes of the corresponding calibration plot (Table 7).

The results obtained from the above set of observations prove that the method is useful in routine qualitative and quantitative analysis of the markers from the complex herbal mixture formulation. Moreover, various analytical methods for estimation of ellagic acid, quercetin, and piperine were reported alone and in combination with other drugs [4-10], but there is no reported HPLC analysis method for simultaneous estimation of ellagic acid, quercetin, and piperine combination and the novel method developed in this report is the first of its kind. The developed method is based on the use of a very economical solvent, had short chromatographic time, and hence can be performed with ease.

\section{CONCLUSION}

The results indicate that selected ayurvedic dental powder contains a number of markers that may be responsible for its therapeutic activity. The developed HPLC method will assist in the standardization of dental powder using biologically active chemical markers. This novel developed HPLC method for simultaneous determination of ellagic

Table 4: Method precision results (Vithoba Ayurvedic dental powder)

\begin{tabular}{|c|c|c|c|c|}
\hline \multirow[t]{2}{*}{ Marker } & \multicolumn{2}{|l|}{ Intraday } & \multicolumn{2}{|l|}{ Interday } \\
\hline & Average content $(\mathrm{ppm}) \mathrm{n}=3$ Mean $\pm S D$ & \% RSD & Average content $(\mathrm{ppm}) \mathrm{n}=3$ Mean \pm SD & $\%$ RSD \\
\hline Ellagic acid & $7.03 \pm 0.07$ & 1.06 & $7.09 \pm 0.07$ & 1.11 \\
\hline Piperine & $4.45 \pm 0.01$ & 0.22 & $4.41 \pm 0.05$ & 1.26 \\
\hline
\end{tabular}

\#n: Number of injections, "SD: Standard deviation, "\# RSD: Percent relative standard deviation

Table 5: Recovery study for three markers in dental powder

\begin{tabular}{|c|c|c|c|c|c|c|}
\hline Compounds & $\begin{array}{l}\text { Sample } \\
\text { content (ppm) }\end{array}$ & $\begin{array}{l}\text { Standard } \\
\text { added (ppm) }\end{array}$ & $\begin{array}{l}\text { Actual } \\
\text { amount (ppm) }\end{array}$ & $\begin{array}{l}\text { Total average } \\
\text { area found }(n=3)\end{array}$ & $\begin{array}{l}\text { Amount } \\
\text { recovered (ppm) }\end{array}$ & \% Recovery \\
\hline \multirow[t]{3}{*}{ Ellagic acid } & 3.50 & 2.80 & 6.30 & 1049566 & 6.46 & 102 \\
\hline & & 3.50 & 7.00 & 1099009 & 7.07 & 101.06 \\
\hline & & 4.20 & 7.70 & 1168448 & 7.90 & 102 \\
\hline \multirow[t]{3}{*}{ Quercetin } & 1.64 & 1.31 & 2.95 & 386810 & 2.91 & 98.86 \\
\hline & & 1.64 & 3.28 & 387645 & 3.26 & 99.64 \\
\hline & & 1.96 & 3.60 & 389989 & 3.56 & 98.92 \\
\hline & & 2.23 & 4.46 & 416708 & 4.46 & 100.18 \\
\hline & & 2.67 & 4.90 & 476763 & 4.82 & 98.46 \\
\hline
\end{tabular}

${ }^{n} \mathrm{n}:$ Number of injections

Table 6: Robustness data for ellagic acid, quercetin, and piperine

\begin{tabular}{|c|c|c|c|c|c|c|}
\hline \multirow[t]{2}{*}{ Parameters } & \multicolumn{2}{|c|}{ Ellagic acid (10 ppm) } & \multicolumn{2}{|c|}{ Quercetin (7 ppm) } & \multicolumn{2}{|c|}{ Piperine (8 ppm) } \\
\hline & Peak area & Tailing factor & Peak area & Tailing factor & Peak area & Tailing factor \\
\hline Minus temperature $\left(33^{\circ} \mathrm{C}\right)$ & 1356692 & 1.02 & 405178 & 0.98 & 1085821 & 1.03 \\
\hline Plus temperature $\left(37^{\circ} \mathrm{C}\right)$ & 1356786 & 1.00 & 408768 & 0.97 & 1086763 & 0.99 \\
\hline Minus flow rate $(1.1 \mathrm{ml} / \mathrm{min})$ & 1356825 & 1.08 & 404863 & 1.00 & 1088648 & 1.26 \\
\hline Plus flow rate $(1.3 \mathrm{ml} / \mathrm{min})$ & 1357687 & 1.09 & 405283 & 1.21 & 1086746 & 1.00 \\
\hline Minus wavelength (254 nm) & 1357358 & 0.99 & 405834 & 0.93 & 1086476 & 1.17 \\
\hline Plus wavelength $(256 \mathrm{~nm})$ & 1367846 & 1.37 & 406834 & 0.82 & 1086547 & 1.09 \\
\hline
\end{tabular}


Table 7: LOD and LOQ for ellagic acid, quercetin, and piperine

\begin{tabular}{lll}
\hline Marker & LOD (ppm) & LOQ (ppm) \\
\hline Ellagic acid & 0.60 & 1.84 \\
Quercetin & 0.45 & 1.60 \\
Piperine & 0.15 & 0.47 \\
\hline
\end{tabular}

"LOD: Limit of detection, "LOQ: Limit of quantitation

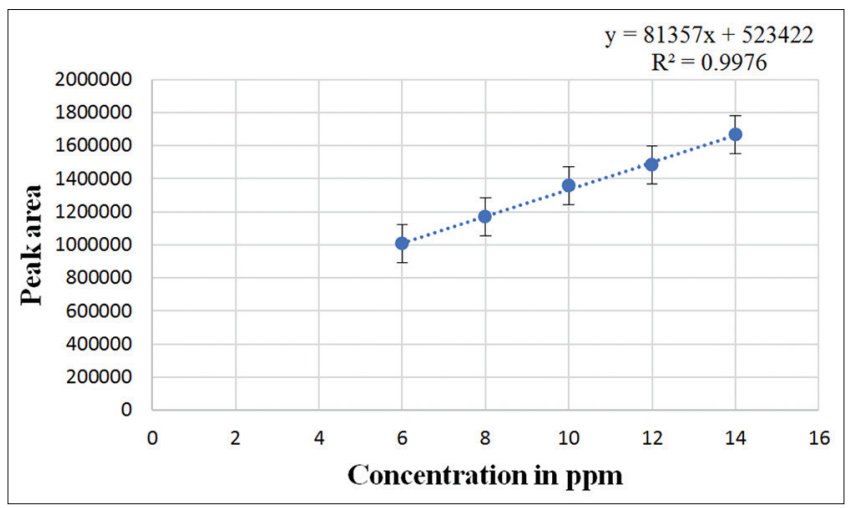

Fig. 7: Calibration curve of ellagic acid

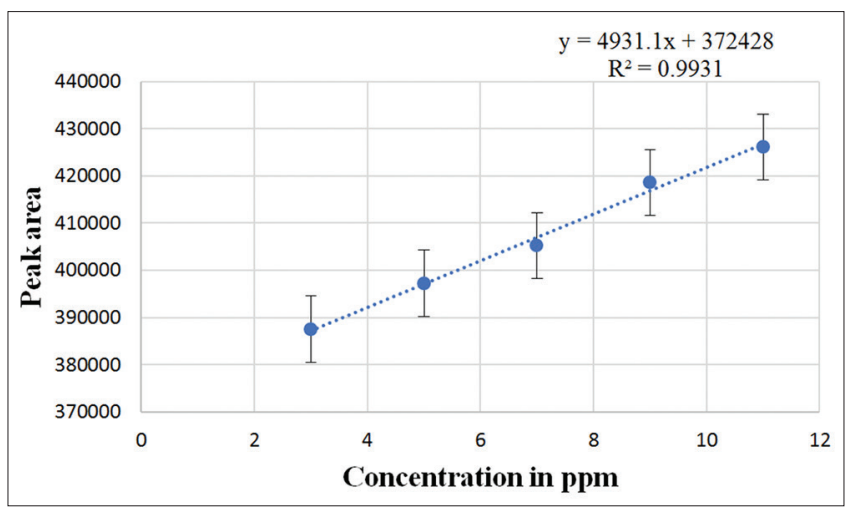

Fig. 8: Calibration curve of quercetin

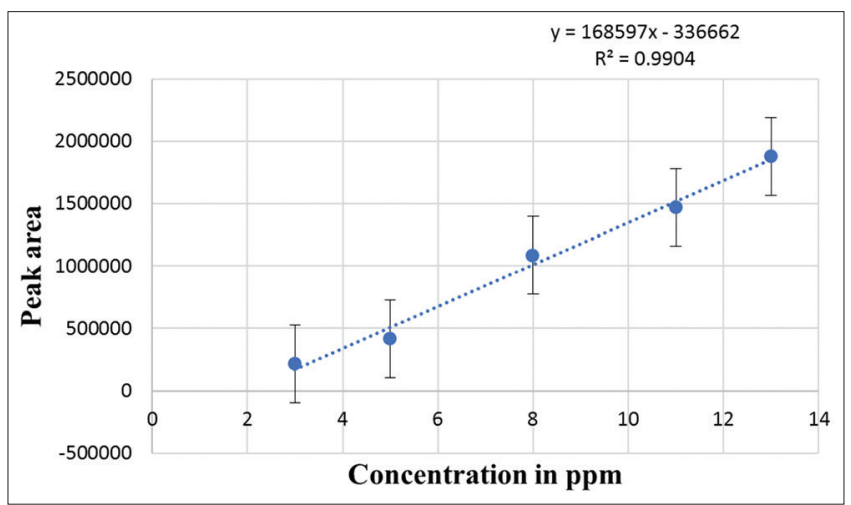

Fig. 9: Calibration curve of piperine

acid, quercetin, and piperine from ayurvedic dental powder is accurate, precise, reproducible, and repeatable. These ayurvedic dental powders also contain a number of other constituents, which are currently the subject of further investigation, apart from those standards studied. With the growing demand for herbal drugs and increased belief in the use of herbal medicine, the development of a standardization tool will help in maintaining the quality of this important ayurvedic preparation.

\section{ACKNOWLEDGMENT}

Authors are thankful to Yucca Enterprises, Mumbai, Maharashtra, for providing gift samples.

\section{AUTHORS' CONTRIBUTIONS}

All the authors have contributed equally.

\section{CONFLICT OF INTEREST}

Declared none.

\section{REFERENCES}

1. Ong ES. Extraction methods and chemical standardization of botanicals and herbal preparations. J Chromatogr B Anal Technol Biomed Life Sci 2004; 812:23-33.

2. Asokar LV, Kakkar KK, Chakra OG. Glossary of Indian medicinal plants with active principles, Publication and Information Directorate, New Delhi, 1992, p. 122

3. Quality Standards of Indian Medicinal Plants, Vol. I, Indian Council of Medical Research, New Delhi, 2003, pp. 10-50.

4. Nowak R. Determination of ellagic acid in pseudofruits of some species of roses. Acta Pol Pharm 2006; 63:289-92.

5. Tiwari P, Patel RK. Quantification of gallic acid and ellagic acid in arjunarishta by validated HPTLC densitometry. Int J Pharm Sci Res 2012; 03:2215-23.

6. Walid E, Hassan M, Mona M. HPLC analysis of quercetin and antimicrobial activity of comparative methanol extracts of shinus molle L. Int J Curr Microbiol App Sci 2015; 04:550-8.

7. Lee FA, Mun FY, Yvonne T, Peh K, Yusrida D. HPLC method for simultaneous quantitative detection of quercetin and curcuminoids in traditional chinese medicines. J Pharmacopuncture 2014; 17:36-49.

8. Bajad S, Singla AK, Bedi KL. Liquid chromatographic method for determination of piperine in rat plasma: Application to pharmacokinetics. J Chromatogr B Anal Technol Biomed Life Sci 2002; 776:245-9.

9. Kapuriya KG, Parmar PM, Topiya HR, Faldu SD. Method development and validation of rifampicine and piperine in their combined dosage form. Int Bull Drug Res 2012; 01:71-80.

10. Shah U, Jasani A. UV spectrophotometric and RP-HPLC methods for simultaneous estimation of isoniazid, rifampicin and piperine in pharmaceutical dosage form. Int J Pharm Pharm Sci 2014; 06:274-80.

11. Vemula VR, Sharma PK. RP-HPLC method development and validation for simultaneous estimation of diclofenac and tolperisone in tablet dosage form. Asian J Pharm Clin Res 2013; 06 Suppl 3:186-9.

12. Shah R, Shah R. Development and validation of RP-HPLC method for phenytoin sodium and phenobarbitone in bulk and pharmaceutical dosage form. Int J Pharm Pharm Sci 2017; 09:224-9.

13. International Conference on Harmonization of Technical Requirements for Registration of Pharmaceuticals for Human use. Validation of Analytical Procedures: Text and Methodology ICH Q2 (R1); 2005.

14. Sarat M, Murali PK and Rambabu C. Development and validation of RPHPLC method for simultaneous estimation of amlodipine besylate and benazepril Hcl in tablet dosage form. Int J Curr Pharm Res 2012; 04:80-4.

15. Madhukar A, Kannappan N, Kumar CB. Analytical method development and validation for the determination of hydrochlorothiazide, amlodipine besylate and telmisartan hydrochloride in multicomponent tablet dosage form and in biorelevant media (fassif) by RP-HPLC techniques. Int J Pharm Pharm Sci 2015; 07:218-25.

16. FDA, Guidance R. Validation of chromatographic methods. center for drug evaluation and research (CDER), Food and Drug Administration; 1994. p. 2.

17. FDA, ORA validation and verification guidance for human drug analytical methods. Food and Drug Administration; 2003. p. 1. 